
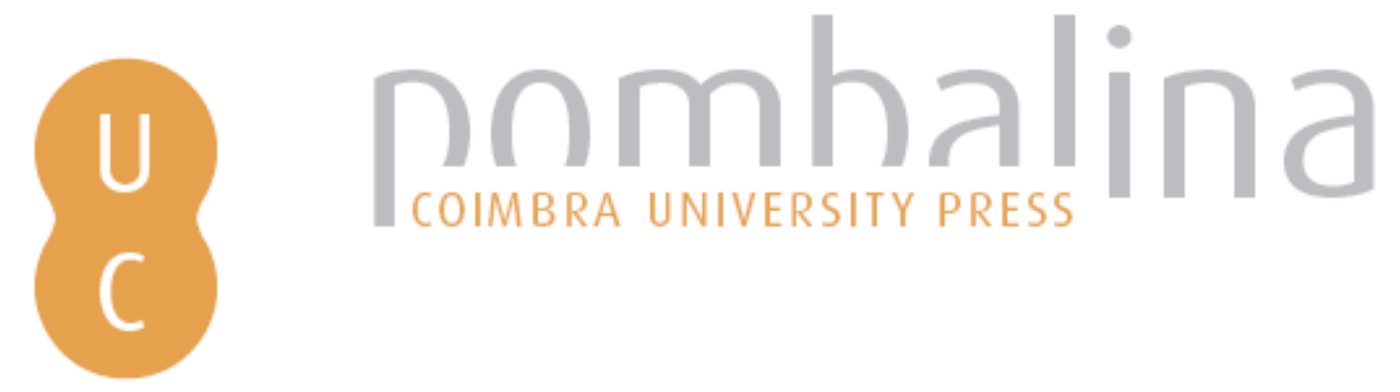

\title{
José da Costa Azevedo e Custódio Alves Serrão: da formação na Universidade de Coimbra à estruturação do Museu Nacional no Brasil
}

Autor(es): $\quad$ Fernandes, Antonio Carlos Sequeira; Henriques, Deise Dias Rêgo

Publicado por: Imprensa da Universidade de Coimbra

URL

persistente: URI:http://hdl.handle.net/10316.2/38450

DOI: $\quad$ DOI:http://dx.doi.org/10.14195/978-989-26-0764-1_14

Accessed : $\quad$ 26-Apr-2023 08:46:00

A navegação consulta e descarregamento dos títulos inseridos nas Bibliotecas Digitais UC Digitalis, UC Pombalina e UC Impactum, pressupõem a aceitação plena e sem reservas dos Termos e Condições de Uso destas Bibliotecas Digitais, disponíveis em https://digitalis.uc.pt/pt-pt/termos.

Conforme exposto nos referidos Termos e Condições de Uso, o descarregamento de títulos de acesso restrito requer uma licença válida de autorização devendo o utilizador aceder ao(s) documento(s) a partir de um endereço de IP da instituição detentora da supramencionada licença.

Ao utilizador é apenas permitido o descarregamento para uso pessoal, pelo que o emprego do(s) título(s) descarregado(s) para outro fim, designadamente comercial, carece de autorização do respetivo autor ou editor da obra.

Na medida em que todas as obras da UC Digitalis se encontram protegidas pelo Código do Direito de Autor e Direitos Conexos e demais legislação aplicável, toda a cópia, parcial ou total, deste documento, nos casos em que é legalmente admitida, deverá conter ou fazer-se acompanhar por este aviso.

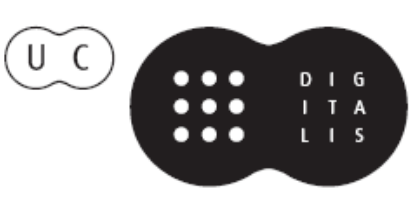


${ }^{1}$ Museu Nacional / Universidade Federal do Rio de Janeiro; Sócio Correspondente Brasileiro da Academia das Ciências de Lisboa

${ }^{2}$ Museu Nacional / Universidade Federal do Rio de Janeiro

acsfernandes@pq.cnpq.br; deiseh@acd.ufrj.br

\author{
José da Costa Azevedo e Custódio Alves Serrão: da Formaçāo na \\ Universidade de Coimbra à Estruturação do Museu Nacional no Brasil
}

\title{
Antonio Carlos Sequeira Fernandes ${ }^{1}$; Deise Dias Rêgo Henriques ${ }^{2}$
}

A chegada da corte ao Brasil em 1808 trouxe inúmeros benefícios administrativos e econômicos para a antiga colônia portuguesa. Entretanto, durante a primeira década de sua presença, o país carecia de uma verdadeira instituição de ciências naturais, o que se concretizou em 1818 com a fundação do Museu Nacional. No início do funcionamento da nova casa a carência de "objetos" naturais era extremamente acentuada e a aquisição e organização de suas coleções tornou-se a principal preocupação de seus primeiros diretores, frei José da Costa Azevedo (1763-1822), João da Silveira Caldeira (1800-1854) e frei Custódio Alves Serrão (1799-1873), que estiveram à frente da instituição no período de 1818 a 1847 . Dos três, os frades José da Costa Azevedo e Custódio Alves Serrão, dedicaram-se aos estudos das ciências naturais na Universidade de Coimbra, especializando-se em mineralogia. No Brasil, Costa Azevedo atuou como responsável pelo gabinete mineralógico da Academia Militar e, como diretor do Museu Nacional, foi o primeiro a cuidar da coleção Werner, expressiva coleção de minerais transferida da referida academia e primeiro acervo mineralógico da instituição. Alves Serrão, por sua vez, também atuou como professor de Mineralogia na Academia Militar e, em sua gestão como diretor do museu, foi particularmente ativo no enriquecimento do acervo da instituição, incluindo exemplares geopaleontológicos. Levantamento realizado no acervo atual do Departamento de Geologia e Paleontologia revelou a permanência de inúmeros exemplares adquiridos por ocasião de suas gestões, acervo que hoje se revela de grande importância histórica e científica para o Museu Nacional.

\section{A INSTITUIÇÃo}

O Museu Nacional, uma unidade da Universidade Federal do Rio de Janeiro (UFRJ) é uma instituição brasileira rica em memória e produção científica e de caráter educacional. Aberto ao público, ele abriga um rico patrimônio museológico, histórico e científico em sua reserva técnica e em suas exposições de longa duração e temporárias.

A exemplo da Universidade de Coimbra que, na segunda metade do século XVIII (1775), instalou a estrutura museal Gabinete de História Natural, visando atender 
a um contexto de "introdução e institucionalização dos estudos das ciências modernas" (BAPTISTA, 2010, p. 52), o Museu Nacional, na figura de seu então diretor Ladislau de Souza Mello e Netto (gestão de 1874 a 1893), implementou cursos, que foram mais tarde substituídos por conferências, além de criar a revista trimestral Os Archivos do Museu Nacional, uma nova via de divulgação científica que permitiu a comunicação e troca com museus estrangeiros (SEÇão DE Museologia, 2011). Paulatinamente a instituição investiu na modernização científica e cultural até que em 1941, em seu novo regimento, se dá a criação do Serviço de Extensão Cultural com a proposta de organizar e divulgar estudos realizados e resultados obtidos e em 1944, a abertura de concursos públicos de provas e títulos para as divisões então existentes (Antropologia, Botânica, Geologia e Ecologia), permitindo o ingresso de novos pesquisadores. Este fato, impulsionou a pesquisa histórica natural e compôs um novo cenário que atenderia a proposta estrutural universitária vindoura: "coligir, classificar e conservar materiais, organizando coleções em séries e exposiçôes públicas; realizar estudos e pesquisas; divulgar conhecimentos e cooperar com as escolas e faculdades da Universidade do Brasil com fins de ensino e pesquisa" (SEÇÃO DE MusEOLOGIA 2011). Foi neste espírito que em 1946 o Museu Nacional foi anexado à Universidade do Brasil. O caminho trilhado até esta configuração institucional teve como base o empenho de personagens como os frades José da Costa Azevedo e Custódio Alves Serrão, cuja base científica se fez reforçada através do aprendizado obtido na Universidade de Coimbra e cuja visão se espelhou na influência do "grande projeto político-econômico, científico e cultural que caracterizou a segunda metade do século XVIII por todo o Império, e do qual a História Natural foi a grande artifice" (LOPES 2005).

\section{Frei José da Costa Azevedo - 1.0 Diretor do Museu Nacional (1818-1822)}

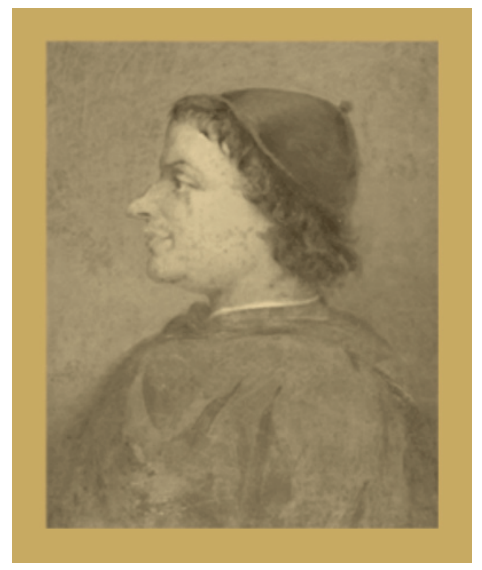

Figura 1 - Frei José da Costa Azevedo (1763-1822). Pintura a óleo exposta na galeria de fotos de ex-diretores do Museu Nacional, no atual Auditório Roquette Pinto, Museu Nacional (prédio do Palácio). Foto do Prof. Dr. Antônio Carlos Sequeira Fernandes. 
O Museu Real foi criado através de um decreto assinado por d. João VI em 06 de junho de 1818, no qual, concomitantemente, criou o cargo de diretor da Instituição, para o qual foi nomeado o filósofo naturalista franciscano frei José da Costa Azevedo (figura 1).

Nascido na cidade do Rio de Janeiro em 16 de setembro de 1763, sua trajetória até alcançar esta honrosa posição, nos remete aos ensinamentos conimbricenses. Escolhido não por acaso, sua formação permitiu obter experiência em diversas instituições científicas, nas quais aprendeu e ensinou a história natural. Fez o curso de Humanidades no Colégio dos Nobres, em Lisboa e cursou Teologia na Universidade de Coimbra, onde frequentou também os cursos de Filosofia e Ciências Naturais (Pataca E Pinheiro, 2005) especializando-se posteriormente em Mineralogia. Curiosamente, nos arquivos da Universidade de Coimbra não se encontram muitas referências a sua passagem pela instituição. Não foi possível encontrar registro de Certidão de Idade, necessária para a realização da matrícula, e os registros de matrícula, com exceção daquele referente ao Segundo Anno Filosófico, datada de 1785-1786 (Livros de Matrículas (1785-1786), Livro 14, fl. 48v) (figura 2).

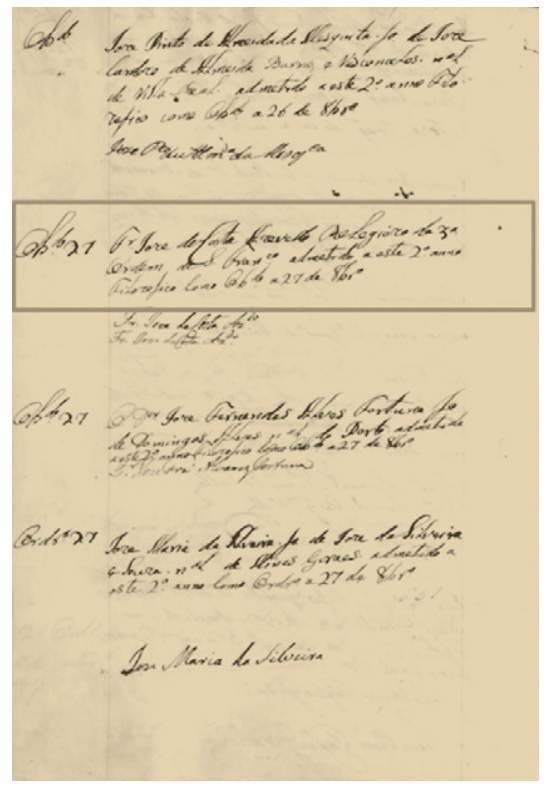

Figura 2 - Documento digitalizado da Matrícula de Frei José da Costa Azevedo no Segundo Anno Filosófico (SR: Livros de Matrículas (1785-1786), Livro 14, fl. 48v). (Documento cedido pelo Serviço de Digitalização da Universidade de Coimbra).

Nomes como Domenico Agostino Vandelli (1735-1816), d. José Joaquim da Cunha de Azeredo Coutinho (1742-1821), d. Rodrigo Domingos de Sousa Coutinho (1755-1812), Manuel Arruda da Câmara (1752-1810) e João da Silva Feijó (1760-1824) estiveram presentes em distintas fases de sua formação. Domenico Vandelli, que era discípulo de Carl von Linné (1707-1778), exerceu influência na formação de vários alunos, destacando-se a passagem de seus conhecimentos e de suas ideias fisiocráticas a d. José Joaquim da Cunha de Azeredo Coutinho, a Manuel Arruda da Câmara e a José da Costa Azevedo. 
Vandelli pôde demonstrar o seu entendimento sobre a história natural e dar a conhecer as instruçôes das "viagens filosóficas", que objetivavam realizar um levantamento dos produtos da natureza em Portugal e suas colônias (Almeida et al. 2008). Dom Azeredo Coutinho, que em 1798 criou o Seminário de Olinda, convidou frei José para atuar na direção da instituição e exercer o cargo de professor de Teologia e de Filosofia, tendo sido o primeiro a ocupá-lo (Almeida et al. 2008). Era o curso secundário mais completo do país e acolhia alunos que não podiam ir à Coimbra fazer seus estudos (FÉrRer, 2008)

Frei José da Costa Azevedo recebeu do Senado de Olinda a incumbência de decidir sobre a "qualidade dos ares respiráveis na Cidade de Olinda e na villa do Recife", produzindo a obra Dissertação chimica sobre a natureza do ar atmospherico que se respira na cidade de Olinda e na villa do Recife Pernambuco. Atuou também na área da Física Experimental, sendo o primeiro professor a atuar à frente da disciplina (ALMEIDA et al. 2008). Dom Rodrigo de Sousa Coutinho, o barão de Linhares, foi um nobre que acompanhou a transferência da corte portuguesa para o Brasil e o fundador, em 1810, da Academia Real Militar. Quando de sua criação, o referido conde convidou frei José para participar da mesma. Foi nomeado, por decreto de lei, como professor de Mineralogia (6. ${ }^{\circ}$ Ano) e de História Natural (7. ${ }^{\circ}$ Ano) atuando como administrador do Gabinete dos Produtos de Mineralogia e História Natural da academia (PATACA e Pinheiro 2005; Teles 2003). Manuel Arruda da Câmara, que em 1783 (data possível, não confirmada) matriculou-se na Universidade de Coimbra e formou-se em Filosofia Natural, foi incumbido pela Coroa portuguesa de realizar estudos sobre a natureza da região nordeste da colônia. Empenhou-se em levantamentos científicos sobre mineralogia, botânica e zoologia e redigiu artigos ilustrados por ele e por frei João Ribeiro Pessoa de Melo Montenegro (1766-1817), um dos mártires da Revolução Pernambucana (também conhecida como a Revolução dos Padres) de 6 de março de 1817 e responsável pelos desenhos de história natural. Chama a atenção a obra Flora pernambucana que apresenta não só desenhos dos ilustres citados, mas também de frei José da Costa Azevedo (Aguiar 2011). Segundo Kury (2004), um caderno pertencente à Arruda da Câmara, "composto de um volume original acrescido de folhas coladas com desenhos e descriçôes de vegetais" contém um desenho de uma planta da família Leguminosae, a Lafonia bilobata (atualmente Bauhinia rubiginosa), nome dado em homenagem ao duque de Lafões, feito por e com dedicatória de frei José da Costa Azevedo. João da Silva Feijó foi enviado à capitania do Ceará em 1799 para realizar um levantamento da história natural local, dando ênfase aos aspectos da mineração, mineralógicos e geológicos, permanecendo na região até 1818 quando foi para o Rio de Janeiro. Lá chegando, se apresentou como lente de Historia Natural na Academia Militar do Rio de Janeiro, ano em que frei José foi nomeado professor (PATACA E PinHeiro 2005). Em 1822, Feijó solicitou à José Bonifácio de Andrada e Silva (1763-1838) que lhe cedesse salas no Museu Real para ministrar, uma vez por semana, aulas práticas versando sobre História Nacional (Museu Nacional do Rio de Janeiro, doc. 11, pasta 1).

Os documentos gerados a partir das expediçôes científicas e as citaçôes nominais dos naturalistas que se encontravam na colônia revelam, na visão de AGUIAR (2011), que os mesmos mantinham contato e trocavam experiências de informaçôes, fato bastante compreensível e esperado. Neste novo cenário, o Museu Real, já na figura de seu primeiro diretor, frei José da Costa Azevedo, passou a ser a instituição responsável por dar as diretrizes de como "colher, conservar e remeter os objetos de História Natural", 
elaborada em 1819 nos moldes das Instruções do Museu de Paris, por organizar os dados da natureza obtidos nas viagens e por disponibilizar material aos estudiosos. Foi, portanto, na gestão de frei José, que se fez necessário um grande esforço para tornar o novo museu semelhante aos modelos europeus (PATACA E Pinheiro 2005), capaz de receber naturalistas e de fornecer informaçôes sobre os elementos da colônia. Para isso se fazia necessária a busca e o incentivo às novas viagens científicas.

Situado inicialmente no campo de Sant'Anna, o acervo inicial do Museu Real se formou com os remanescentes do acervo da Casa de História Natural (conhecida como “Casa dos Pássaros”), nomeadamente produtos de história natural, artefatos indígenas, armários, instrumentos e coleções mineralógicas. Curiosamente a Academia Real Militar, que havia recebido em 1813 o acervo da Casa de História Natural, criou em 1818 [mesmo ano em que frei José foi nomeado diretor do museu], um gabinete de produtos de mineralogia e história natural e nomeou frei José da Costa Azevedo para lente de história natural, o qual passaria também a exercer a cadeira de mineralogia (SEÇÃO De Museologia 2011). Fazia parte das coleções mineralógicas a expressiva coleção de minerais conhecida como coleção Werner (Fig. 3), acervo (parcial) organizado pelo mineralogista alemão Abraham Gottlob Werner (1749-1817) que foi adquirido do barão Karl Eugen Pabst von Ohain (1718-1784), assessor de minas da Academia de Minas de Freiberg (Alemanha), pela Coroa portuguesa, "provavelmente em 1805, por ordem de Antônio de Araújo de Azevedo - o conde da Barca -, ministro dos Estrangeiros e da Guerra, para o Museu de História Natural de Lisboa” (Lopes 1997, pp. 27-28). No Brasil, a coleção Werner, com 3326 exemplares, teria ido para o então Arsenal de Guerra, sendo integrada à Real Academia Militar desde sua fundação em 1810 e, por fim, incluída no acervo do Museu Real. Frei José teve a oportunidade de atuar na curadoria deste material e foi autor da obra "Elementos de Mineralogia, segundo o método Werner". Em 1819, transferiu esta coleção para a maior sala do prédio do museu devido a sua importância e abriu ao público, inicialmente, duas salas apresentando modelos de máquinas industriais. Ainda no mesmo ano as salas superiores foram abertas ao público, por um dia na semana. Em 1821, frei José da Costa Azevedo foi o responsável pela abertura do museu às exposições públicas (SEÇÃo DE MusEOLOGIA 2011).

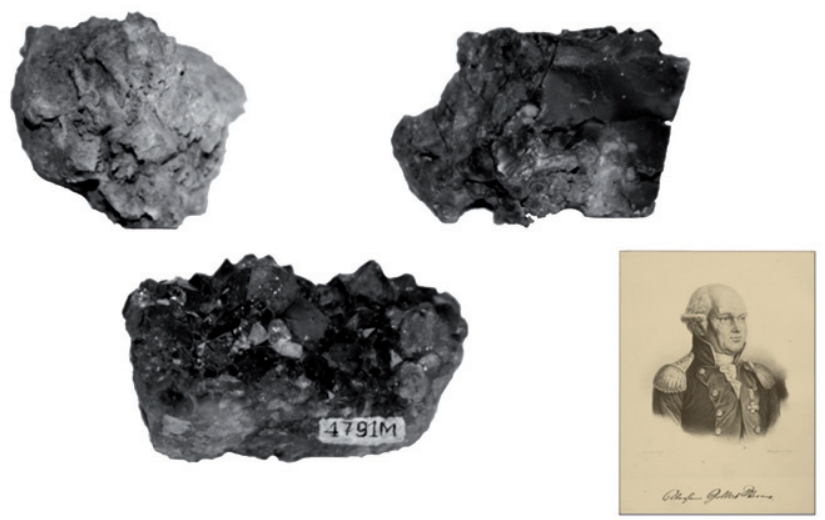

Figura 3 - Minerais da Coleção Werner (Museu Nacional do Rio de Janeiro). 
Infelizmente, não há registros significativos de outras entradas de material, nomeadamente aquelas referentes à história natural. No Livro dos Ofícios Correspondência Oficial 1819/1842, do acervo da Seção de Memória e Arquivo (SEMEAR) do Museu Nacional, poucos são os registros feitos à época de Frei José, que em todos os ofícios subscreve como Inspetor e Diretor do Muzeo. O segundo ofício apontado no referido livro registra a cópia transcrita da solicitação de guarda e mostra das máquinas adquiridas por Ignácio Álvares Pinto de Almeida, secretário da Junta de Comércio. Mais tarde mencionou a vontade de ampliar o acervo exposto e referiu-se aos "engenhos de extrahir, dobar, e torcer a mesma seda" ojetivando que "o Público fique sciente deste objecto". Reflete-se aqui a preocupação do diretor em difundir o conhecimento adquirido nos bastidores da casa. Os demais ofícios demonstram sua preocupação com as obras do museu necessárias para ampliar o espaço de reserva técnica.

Frei José Batista da Costa faleceu em 7 de novembro de 1822, mas em março de 1842 , em função do decreto de 1842 , recebeu postumamente o título de Doutor, conferido aos lentes jubilados (Teles, 2003). Homenagem merecida para aquele que lutou por um novo ideal e permitiu a inicial manutenção da casa de ciência Museu Real. Com a sua morte, João de Deus de Mattos (?-?), que havia sido preparador, porteiro e guarda da instituição, assumiu provisoriamente o cargo de diretor até 1823 . Na sua gestão somou-se ao acervo uma coleção de tucanos, por doação de José Bonifácio, em nome do imperador (SEÇÃo DE Museologia 2011).

Em 1823, a direção do então Museu Nacional e Imperial ficou a cargo de João da Silveira Caldeira (1800-1854) que até o ano 1827 assumiu o posto. Durante este período, em que foi criado o primeiro laboratório químico, presenciou-se o notável crescimento do acervo do museu, graças ao incentivo da vinda de naturalistas a esta casa de ciência, que passou a ter um caráter consultivo. Nomeia-se aqui a oferta da coleção de mamíferos e aves da Europa feita ao museu pelo barão Georg Heinrich von Langsdorff (1774-1852); o acervo egípcio de grande representatividade; e objetos etnográficos (SEÇÃo DE Museologia 2011). Assim como frei José, Silveira Caldeira mostrou preocupação com armazenamento do acervo e indicou em ofício datado de 23 de dezembro de 1823 que "Frei José da Costa Azevedo, então Diretor, viase na necessidade de os arrumar huns sobre os outros", e solicitou a "S. Mg. ${ }^{\text {de }}$ para que fosse servido Mandar continuar as obras do Muzeo, então paradas..." Foi este o cenário encontrado por Custódio Alves Serrão, que dirigiu o Museu Imperial e Nacional no período de 1828 a 1847 .

\section{Frei Custódio Alves da Pureza Serrão - 3.0 Diretor do Museu Nacional (1828-1847)}

Considerado o terceiro diretor, por ter João de Deus de Mattos assumido apenas interinamente o cargo, frei Custódio Alves da Pureza Serrão (figura 4), assim como o frei José da Costa Azevedo, nos remete aos ensinamentos conimbricenses. 


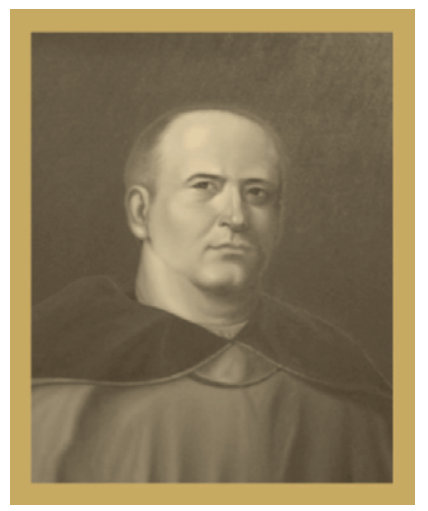

Figura 4 - Frei Custódio Alves da Pureza Serrão. Pintura à óleo exposta na galeria de fotos de ex-diretores do Museu Nacional, no atual Auditório Roquette Pinto, Museu Nacional (prédio do Palácio). Foto do Prof. Dr. Antônio Carlos Sequeira Fernandes.

Nascido em 1799, na então vila de Alcântara, localizada no estado do Maranhão, ingressou na Universidade de Coimbra em 1817, onde dedicou-se aos estudos de Ciências Naturais e formou-se professor de Física e Química.

Nos arquivos da Universidade de Coimbra os documentos referenciados a sua passagem pela instituição são: Certidão de Idade (SR: Certidōes de Idade (1772-1833) Vol. 10, fl. 70) (figura 5); e os registros de matrículas referentes ao Primeiro Anno Filosófico (SR: Livros de Matrículas (1819-1820), Livro 47, fl. 280v) (figura 6a); ao Segundo Anno Filosófico (SR: Livros de Matrículas (1820-1821), fl. 285) (figura 6b); ao Terceiro Anno Filosófico (SR: Livros de Matrículas (1821-1822), fl. 344v) (figura 6c); e ao Quarto Anno Filosófico (SR: Livros de Matrículas (1822-1823), fl. 546) (figura 6d).

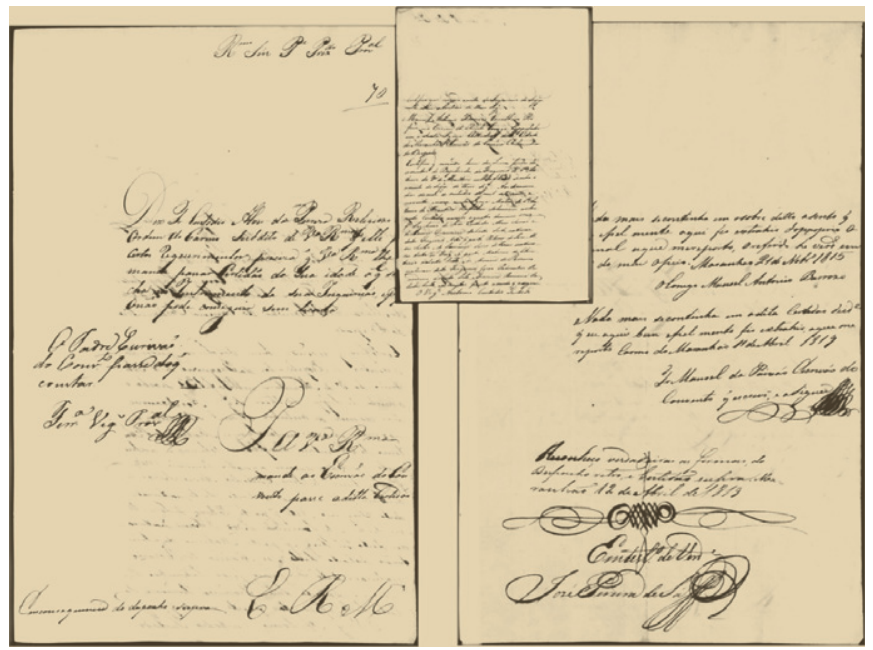

Figura 5 - Documento digitalizado da Certidão de Idade de Frei Custódio Alves da Pureza Serrão (SR: Certidões de Idade (1772-1833), Vol. 10, fl. 70). (Documento cedido pela Universidade de Coimbra). 


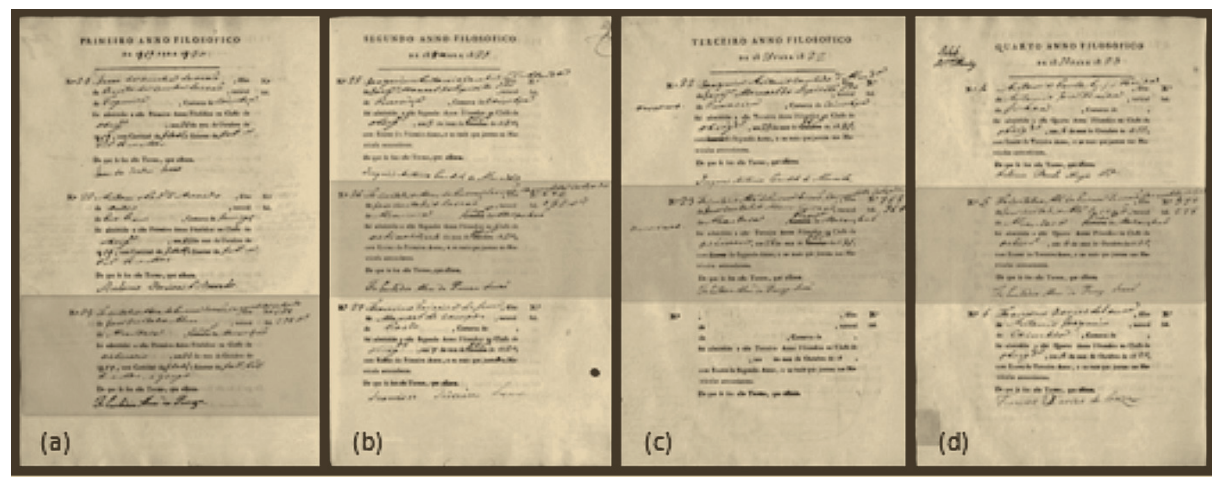

Figura 6 - Documentos digitalizados das Matrículas de Frei Custódio Alves da Pureza Serrão no (a) Primeiro Anno Filosófico (SR: Livros de Matrículas (1819-1820), Livro 47, fl. 280v);

(b) Segundo Anno Filosófico (SR: Livros de Matrículas (1820-1821), fl. 285); (c) Terceiro Anno Filosófico (SR: Livros de Matrículas (1821-1822), fl. 344v); (d) Quarto Anno Filosófico (SR: Livros de Matrículas (1822-1823), fl. 546). (Documentos cedidos pela Universidade de Coimbra).

Frei Custódio foi nomeado diretor do Museu Nacional e Imperial em 26 de janeiro de 1828 quando já atuava como lente de Zoologia e Botânica na Imperial Academia Militar. Em sua gestão atuou como curador e pesquisador do acervo da coleção que se tornava cada vez mais engrandecido. Já nos primeiros anos de sua gestão há a remessa de "conchas perolíferas remetidas pelo Presidente de Goyas" (Livro dos Ofícios - Correspondência Oficial 1819/1842, ofício datado de 29/12/1829, págs.56,57,58); de nódulos vindos da Bahia trazidos pelo viajante baiano Antônio Muniz de Souza (1782-1857) (Livro dos Ofícios - Correspondência Oficial 1819/1842, ofício datado de 09/02/1828, pág. 58); remessa, em 1929, de coleção proveniente do Pará, referente a produtos manufaturados indígenas (vestimentas, armas e utensílios) (Livro dos Ofícios - Correspondência Oficial 1819/1842, ofício datado de 10/03/1829, pág.59). Sobre os manufaturados indígenas frei Custódio fez um relato em ofício enviado à Sua $\mathrm{Mg} .{ }^{\text {de }}$, parte do qual segue aqui descrito:

“... que exigindo de mais $\mathrm{m} .{ }^{\text {ta }}$ Constancia no trabalho, mostrão os recursos $\mathrm{q}^{\mathrm{e}}$ se podem vir a tirar dessas tribus, ao mesmo tempo $\mathrm{q}^{\mathrm{e}}$ dão a mais bella Idea da riqueza dos logares aonde habitão pelo preço e variedade dos diversos materiais de $\mathrm{q}^{\mathrm{e}}$ são formados todos os seus effeitos... Constão tãobem as collecções de Productos Zoológicos, Quadrúpedes, Aves, alguns reptis, e insectos, que pertencentes ao climas do equador, e aos logares regados de grandes rios difficil será encontral os nas outras Províncias do Império, e alguns concentrados nas mattas virgens, ou nas cabeceiras dos grandes rios realção tanto de valor q. ${ }^{\text {to }}$ he o trabalho que se deve suppor p. ${ }^{a}$ as haver colligido. Mas não he o deleite que trazem a uma mera curiosidade estes productos variados que lhe dão toda a importância, he sim $\mathrm{p}^{\mathrm{r}} \mathrm{q}^{\mathrm{e}}$ quando a natureza multiplica a vida debaixo de tantas formas diversas he de essencia suppor se $\mathrm{q}^{\mathrm{e}}$ ella tem fornecido os meios de a sustentar, e estes meios relativam. ${ }^{\mathrm{e}}$ ao homem he sempre indicio de qe serão tãobem variadas as suas commodidades. Vem finalmente, em uma das collecçôes amostras de madeiras, resinas, e junctam. ${ }^{e}$ alguns productos mineraes: todos estes objectos são de um interesse reconhecido para o Brazil, as madeiras, podendo pelas suas diversas qualidades prestar-se a todo o genero de obras, e os mineraes entre os quaes a pedra calcarea e um amalgama de mercúrio...". (Livro dos Ofícios - Correspondência Oficial 1819/1842, ofício datado de 3/04/1829, pp. 62, 63, 64) 
Concomitante ao cargo de diretor passou a ser, em 1833, responsável pela disciplina de Mineralogia na Escola Militar (antiga Academia). Foi primeiro diretor da Terceira Seção (a de Mineralogia, Geologia e Ciências Físicas) e interinamente a de Numismática e Arqueologia, entre os anos de 1842 e 1847, ano em que se afasta da direção do museu (SeÇão de Museologia 2011).

Durante a sua gestão, em 3 de janeiro de 1842, foi elaborado o primeiro regimento do museu e, assim, uma organização da instituição em seçôes, visando uma melhor classificação e conservação dos objetos (SEÇão De Museologia 2011). Frei Custódio incentivou a formação de um acervo voltado para produtos nacionais. O motivo era a frustração por parte de naturalistas estrangeiros, nomeadamente François Louis Nompar de Caumont La Force (1810-1880), conde de Castenau, e o médico e botânico escocês George Gardner (1812-1849), e mesmo naturalistas brasileiros que buscavam conhecer a variedade natural do país. A luta pela melhoria do acondicionamento da coleção continuava em sua gestão tendo em vista o seu "péssimo estado de conservação" (DiCIONÁRIO Histórico-Biográfico das Ciências da Saúde no Brasil 1832-1930). No ano de 1838 o museu contava em seu acervo com " 4.964 produtos zoológicos, 1.600 botânicos, 4.516 mineralógicos (sem incluir 117 diamantes e as amostras de formação aurífera do Brasil), 1.105 moedas e medalhas, 62 quadros, 30 modelos de máquinas industriais, 5.181 instrumentos de física e química e cerca de 500 peças de arqueologia e etnografia.". Neste mesmo ano foram doadas pela família Andrada e Silva as coleçōes mineralógicas e de modelos de máquinas que tinham pertencido a José Bonifácio, fato comunicado à corte por correspondência na qual constava a relação desses objetos (Livro dos Ofícios - Correspondência Oficial 1819/1842, ofício de 31/07/1838, p. 154). Ao terminar a sua gestáo deixou a casa pronta para atender a um modelo organizacional de crescimento, com divisões próprias de cada grupo do acervo.

Frei Custódio faleceu em 10 de março de 1873. Em futuro que não pôde presenciar, o Museu Nacional encontra-se dividido em departamentos (Antropologia, Botânica, Entomologia, Geologia e Paleontologia, Invertebrados, Vertebrados), além de seçôes como a de Memória e Arquivo (SEMEAR) e a de Assistência ao Ensino (SAE), zelando pela curadoria e divulgação científica e educacional.

\section{CONSIDERAÇôES FINAIS}

Como bem resumiu Lopes (2005, p. 1), a História Natural, na metade do século, "ganhou características universalistas, prioridade de ordens política, social, moral" e era entendida de maneira extensiva. Segundo a autora alguns dos filósofos naturais consideravam a "expressão ciências naturais" limitada às disciplinas chamadas naturalistas (stricto sensu): mineralogia, botânica e zoologia. A paleontologia e a antropologia ainda eram disciplinas em construção e nesse contexto, onde observa-se a quase ausência de estudos relativos aos fósseis, pode-se verificar a importância das coleções mineralógicas, das quais o Departamento de Geologia e Paleontologia do Museu Nacional mantém com orgulho a guarda da expressiva Coleção Werner e de outros minerais. Infelizmente muito do acervo foi perdido durante as mudanças de instalações da sede do Museu Nacional e é objetivo atual (projeto coordenado pelo primeiro autor) a busca de pelo menos parte deste material. A influência do vertente conimbrense e do 
pensamento de incentivo às ciências naturais através da atuação dos ex-diretores desta casa de ciências reflete-se no que hoje é a instituição Museu Nacional, uma casa de Ciência dedicada a fomentar o estudo e a pesquisa.

\section{Agradecimentos}

Ao Conselho Nacional de Desenvolvimento Científico e Tecnológico (CNPq, Proc. 401762/2010-6/ Edital Fortalecimento da Paleontologia Nacional e 301328/2009-9/ Bolsa de Produtividade em Pesquisa). A Pedro Miguel Callapez (Universidade de Coimbra) pelo auxílio no acesso à documentação do Arquivo Histórico da Universidade de Coimbra, e a Pedro Rêgo Henriques pela complementação da pesquisa documental.

\section{REFERÊNCIAS}

AGUIAR, José Otávio - Quando o Iluminismo Científico herborizava: Manuel Arruda da Câmara e seus escritos botânicos. In Congresso Internacional Pequena Nobreza nos impérios Ibéricos de Antigo Regime [em linha]. Lisboa [consult. em 24 de Set. 2011]. P. 1-27. Disponível em WWW: <URL:http://www.iict.pt/pequenanobreza/arquivo/Doc/p2-01.pdf

ALMEIDA, Argus Vasconcelos de; MAGALHĀES, Francisco de Oliveira; CÂMARA, Cláudio Augusto Gomes da; SILVA, Jadson Augusto de Almeida da - Pressupostos do ensino da Filosofia Natural no Seminário de Olinda (1800-1817). Revista Eletrónica de Enseñanza de las Ciencias [em linha] 7:2 (2008) 480-505. [Consult. 23 Set. 2011]. Disponível em WWW: <URL: http://www.saum.uvigo.es/reec/volumenes/volumen7/ART12_Vol7_N2.pdf

BATISTA, Maria Teresa de Almeida Martins - O Gabinete de História Natural da Universidade de Coimbra. In: BRANDĀO, José Manuel, ed., [etc.]. Colecçôes e Museus de Geologia : missão e gestão = Collections and Museums of Geology : mission and management. Coimbra: Museu Mineralógico e Geológico da Universidade de Coimbra [etc.] 2010. p. 51-59.

FUNDAÇÃO OSWALDO CRUZ, FIOCRUZ - Dicionário Histórico-Biográfico das Ciências da Saúde no Brasil: 1832-1930 [em linha]. Brasil: Fundação Oswaldo Cruz, [s.d.]. [Consult. 24 Set. 2011]. Disponível em WWW: <URL: http://www.dichistoriasaude.coc.fiocruz.br/iah/P/verbetes/musnac.htm

FÉRRER, Francisco Adegildo - O Seminário de Olinda segundo a historiografia. Revista do Instituto do Ceará. Brasil: [s.n.] Vol. 122 (2008) p. 205-212.

Disponível em WWW: <URL:http://www.ceara.pro.br/Instituto-site/Rev-apresentacao/RevPorAno/2008/09-Art_O\%20seminariodeOlinda.pdfAcesso em 23 de setembro de 2011.

KURY, Lorelai - Homens de ciência no Brasil: impérios coloniais e circulação de informações (1780-1810) História, Ciências, Saúde. Manguinhos. [Em linha]. Vol. 11: 1 (2004), 109-129. [Consult. 25 de Set. 2011]. Disponível em WWW: <http://dx.doi.org/10.1590/S0104-59702004000400006z

LOPES, Maria Margaret - O Brasil descobre a pesquisa científica: os museus e as ciências naturais no século XIX. São Paulo: Hucitec, 1997.

LOPES, Maria Margaret - "Raras petrificaçôes": registros e considerações sobre os fósseis na América Portuguesa. In Congresso Internacional Atlântico do Antigo Regime: poderes e sociedades. [Em linha] Lisboa: Centro de História de Além-Mar [etc.], 2005. [Consult. 23 Set. 2011] Disponível em WWW: <URL:http://cvc.instituto-camoes.pt/ eaar/coloquio/comunicacoes/maria_margaret_lopes.pdf>

PATACA, Ermelinda Moutinho; PINHEIRO, Rachel - Instruções de viagem para a investigação científica do território brasileiro Traveling instructions to the scientific investigation of Brazil]. Revista da Sociedade Brasileira de História da Ciência. Vol. 3:1 (2005) 58-79. [Consult. 23 Set. 2005]. Disponível em WWW:http://www. sbhc.org.br/pdfs/revistas_anteriores/2005/1/ artigos_5.pdf>.

SEÇÃO DE MUSEOLOGIA - Os Diretores do Museu Nacional / UFRJ. [Em linha]. Rio de Janeiro: [s.n.]. [Consult. 23 Set. 2011] Disponível em WWW:URL:http://www.museunacional.ufrj.br/ MuseuNacional/ Principal/ DIRETORES.pdf.

TELES, Pedro Carlos da Silva - O início do ensino da engenharia: a Academia Real Militar, a Escola Central. Boletim da Sociedade Brasileira de Cartografia. [Em linha]. 50 (2003). [Consult. 25 Set. 2011]. Disponível na Internet:URL:http://www.cartografia.org.br/boletim/Boletim50.pdf. 